\title{
A SPECTROFLUORIMETRIC SENSOR BASED ON GRAPE SKIN TISSUE FOR DETERMINATION OF IRON(III)
}

\author{
Minghui Zhang, Baozhan Zheng, Hongyan Yuan ${ }^{*}$ and Dan Xiao* \\ College of Chemical Engineering, Sichuan University, Chengdu 610065, China
}

(Received March 8, 2009; revised October 17, 2009)

\begin{abstract}
A spectrofluorimetric method based on the grape skin has been developed for the determination of $\mathrm{Fe}^{3+}$ at $\mathrm{pH}$ 5.0. The emission wavelength of the grape skin sensor occurs at $680 \mathrm{~nm}$ and the excitation wavelength at $421 \mathrm{~nm}$. The fluorescence of sensor could be quenched by $\mathrm{Fe}^{3+}$ due to the complexing ability of anthocyanin with the metal ions. Anthocyanin, the main pigment in the grape skin, has been found fluorescence sensing material. The sensor based on the grape skin exhibited a calibration response for $\mathrm{Fe}^{3+}$ in two concentration ranges of $1.0 \times 10^{-8}-1.0 \times 10^{-5} \mathrm{M}\left(\mathrm{r}^{2}=0.9888\right)$ and $3.2 \times 10^{-5}-3.2 \times 10^{-4}\left(\mathrm{r}^{2}=0.9856\right) \mathrm{M}$ at $60{ }^{\circ} \mathrm{C}$. The detection limit was found to be $7.5 \times 10^{-9} \mathrm{M}$, and the other common ions did not interfere.
\end{abstract}

KEY WORDS: Grape skin, Fluorescence, Iron(III)

\section{INTRODUCTION}

Spectrofluorimetry has received considerable attention because of its rapid, simple, highly sensitive and selective advantages [1]. At present, some fluorimetric methods for the determination of $\mathrm{Fe}^{3+}$ based on quenching phenomena have been reported. Cha et al. proposed a sensitive procedure for the determination of $\mathrm{Fe}^{3+}$ using salicylic acid as fluorescent reagent. Unfortunately, $\mathrm{Fe}^{2+}, \mathrm{Co}^{2+}, \mathrm{Sm}^{3+}$ and $\mathrm{Y}^{3+}$ ions could cause interference [2]. A selective fluorescent chemosensor for $\mathrm{Fe}^{3+}$ which is composed of water-soluble $\beta$-cyclodextrin and 2,6bis(benzoxazoly)pyridine, was developed by Feng et al. [3]. Askeland et al. isolated a fluorescent pigment from Pseudomonas fluorescens to selectively measure $\mathrm{Fe}^{3+}$ [4]. For the first time, however, we wish to report on the use of grape skin tissue based on fluorescent method for the determination of $\mathrm{Fe}^{3+}$.

Grape is one of the major fruit crops and about $80 \%$ of the produced grape is used in wine making. Wine industry generates about 5-9 million tones grape waste per year [5]. Anthocyanins in grape skins, which are responsible for the red colour of grape and wine, include delphinidin, cyanidin, petunidin, peonidin, malvidin 3-glucosides, 3-(6-acetyl)-glucosides, 3-(6- $p$ coumaroyl)-glucosides, peonidin, malvidin 3-(6-caffeoyl)-glucosides and some pyruvates $[6,7]$. Anthocyanins are currently being associated with health benefits, such as antioxidant and anticancer activity [8]. Two hydroxyl groups or hydroxyl and methoxyl groups in the ortho position can improve the combining capacity of anthocyanins with metallic ions $[9,10]$.

In this work, a natural fluorescent material, the grape skin, was used as a sensor for determination of $\mathrm{Fe}^{3+}$. The spectral characteristics of the sensor and the sensor response to $\mathrm{Fe}^{3+}$ were investigated. In addition, the effects of $\mathrm{pH}$, temperature and foreign ions on the fluorescence intensity were studied. The results reported in the present paper indicated that the spectrofluorimetric sensor based on the grape skin worked well for the determination of $\mathrm{Fe}^{3+}$.

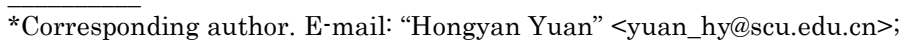
"Dan Xiao" < xiaodan@scu.edu.cn".
} 


\section{EXPERIMENTAL}

Apparatus and reagents

Fluorescence measurements of the grape skin were carried out on a spectrofluorimeter (LS-55, Perkin-Elmer, USA) with a spectrophotometric $1.0 \mathrm{~cm} \times 1.0 \mathrm{~cm}$ quartz cuvette. The scanning rate of monochromators was fixed at $400 \mathrm{~nm} \mathrm{~min}^{-1}$ and the excitation and emission slit widths were set at $10.0 \mathrm{~nm}$ and $15.0 \mathrm{~nm}$, respectively. Morphology of the grape skin was examined by the scanning electron microscopy (SEM, S-4800, Hitachi, Japan).

The standard solution of $\mathrm{Fe}^{3+}$ was prepared by dissolving $\mathrm{FeNH}_{4}\left(\mathrm{SO}_{4}\right)_{2}$ in distilled water. $\mathrm{FeNH}_{4}\left(\mathrm{SO}_{4}\right)_{2}$ was purchased from Kelong Chemical Co. (Chengdu, China). Working solutions were obtained from appropriate dilution of the stock solution. The grape skin pigments $\left(E_{1 \mathrm{~cm}}^{1 \%} 525 \mathrm{~nm} \geq 10\right.$, Pengyuan Co. Qingdao, China) was dissolved in water. $\mathrm{HCl}$ and $\mathrm{NaOH}$ were used to adjust $\mathrm{pH}$ of solutions. The red grape skin used in the sensor construction was purchased from a local market and stored after dryness. All chemicals were of analytical reagent grade and the redistilled water was used throughout.

\section{Sample processing and experimental method}

The pulps of fresh grape were removed by hand, and the grape skins were cleaned with distilled water before drying. Air-dried grape skins were washed with distilled water until they became soft, and then they were cut into smaller pieces using scissors. The coat of the grape skin was mounted on glass slide $(6.0 \mathrm{~cm} \times 1.2 \mathrm{~cm})$. The glass slide with grape skin was winded by Teflon tape, and then fixed to a quartz cuvette filled with $2.0 \mathrm{~mL}$ distilled water. Different concentrations of $\mathrm{Fe}^{3+}$ were added into the cuvette gradually. The volume of $\mathrm{Fe}^{3+}$ solutions added was less than $50 \mu \mathrm{L}$ to keep the total volume of testing solution without obvious change. The fluorescence intensity of the sensor, at an excitation wavelength of $421 \mathrm{~nm}$, was measured at the wavelength of $680 \mathrm{~nm}$.

\section{RESULTS AND DISCUSSION}

The spectral characteristics and main fluorophore of the sensor

After drying at room temperature, the morphological characteristics of the grape skin were examined by scanning electron microscopy (SEM). Figure 1 shows the SEM micrograph for the inner section of the grape skin, which was cleaned with distilled water. The inner surface of grape skin consisted of cross-linked fibrous materials and had many irregular small pores. The thickness, moisture content, fibre content of grape skin would affect the fluorescence intensity of sensor. To obviate this problem, the same kind of grapes and the same section of grape skin were selected to fabricate the sensor. Fortunately, the sensors have the same fluorescence quenching behavior. The excitation and emission spectra of the grape skin-based sensor in the presence of $\mathrm{Fe}^{3+}$ and of sensor alone were also shown in the insert of Figure 1. It was found that the maximal fluorescence excitation and emission wavelengths occurred at $421 \mathrm{~nm}$ and $680 \mathrm{~nm}$, respectively. Therefore, the excitation wavelength at $421 \mathrm{~nm}$ and the emission wavelength at $680 \mathrm{~nm}$ were selected as operating wavelengths for the further studies. The presence of $5.0 \times 10^{-5} \mathrm{M} \mathrm{Fe}^{3+}$ can cause obvious decrease of the fluorescence intensity of the sensor. 


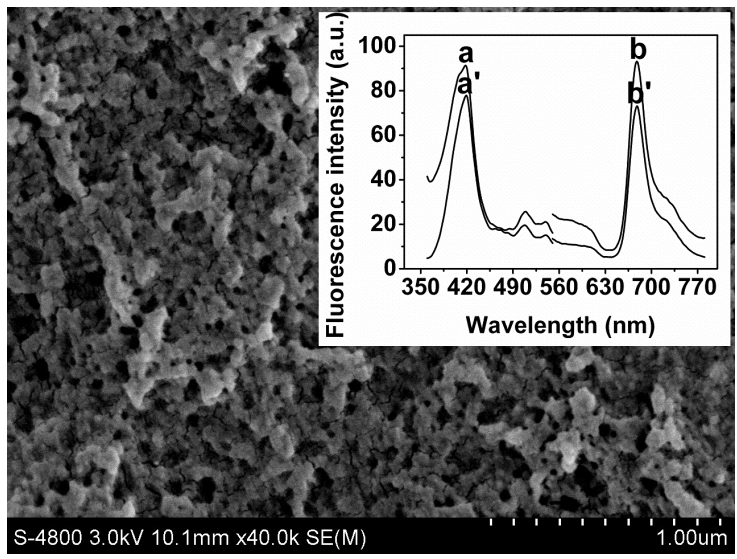

Figure 1. SEM micrograph of the inner surface of grape skin. Inset: fluorescence excitation (a) and emission (b) spectra; a, b: the grape skin-based sensor blank; a', b': adding $5.0 \times$ $10^{-5} \mathrm{M} \mathrm{Fe}^{3+}$ to the system.

\section{Effect of $p H$}

The $\mathrm{pH}$ dependence of the sensor in the presence of $5.0 \times 10^{-5} \mathrm{M} \mathrm{Fe}^{3+}$ solution was studied by using different solutions with $\mathrm{pH}$ range from 5.0 to 7.5. As shown in Figure 2, the fluorescence intensity of the sensor increased with the increase in $\mathrm{pH}$ value from 5.0 to 6.5 and then decreased at $\mathrm{pH}$ value higher than $\mathrm{pH}$ 6.5. Anthocyanins have the different chemical forms depending on the $\mathrm{pH}$ of the solution. At $\mathrm{pH}$ values between 4.0 and 6.0 , four forms of the anthocyanins, flavylium cation, anhydrous quinoidal base, colourless carbinol base and the pale yellow chalcone coexist. When $\mathrm{pH}$ value is higher than 7.0, the anthocyanins are degraded depending on their substituent groups [11]. The degradation of the anthocyanins would affect the fluorescence intensity of grape skin. Since minimum fluorescence intensity occurred at $\mathrm{pH}$ 5.0, $\mathrm{pH} 5.0$ was recommended for further studies.

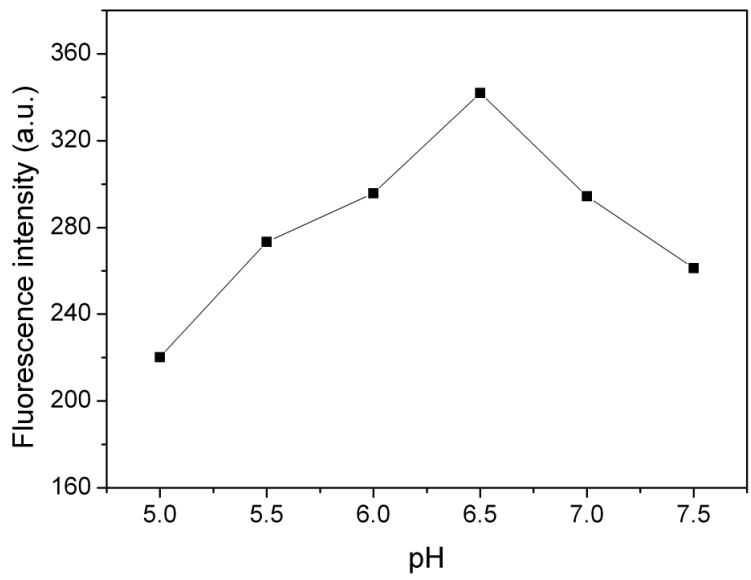

Figure 2. Effect of $\mathrm{pH}$ on the fluorescence intensity of the sensor at $20{ }^{\circ} \mathrm{C}$.

Bull. Chem. Soc. Ethiop. 2010, 24(1) 
Effect of temperature

As the temperature is an important factor in the measuring process, the effect of temperature on the fluorescence intensity of the sensor was studied at various temperatures ranged from 20 to $90{ }^{\circ} \mathrm{C}$. Although the fluorescence quantum yields inherently decreased with the increase in temperature, the ratio of the fluorescence quenching $\left(I_{0} / I\right)$ of the sensor in a given concentration of $\mathrm{Fe}^{3+}\left(2.0 \times 10^{-4} \mathrm{M}\right)$ increased with increasing temperature (Figure 3$)$. When the temperature was higher than $60{ }^{\circ} \mathrm{C}$, the presence of gas bubbles could affect the measurement. Therefore, 60 ${ }^{\circ} \mathrm{C}$ was chosen for further experiments.

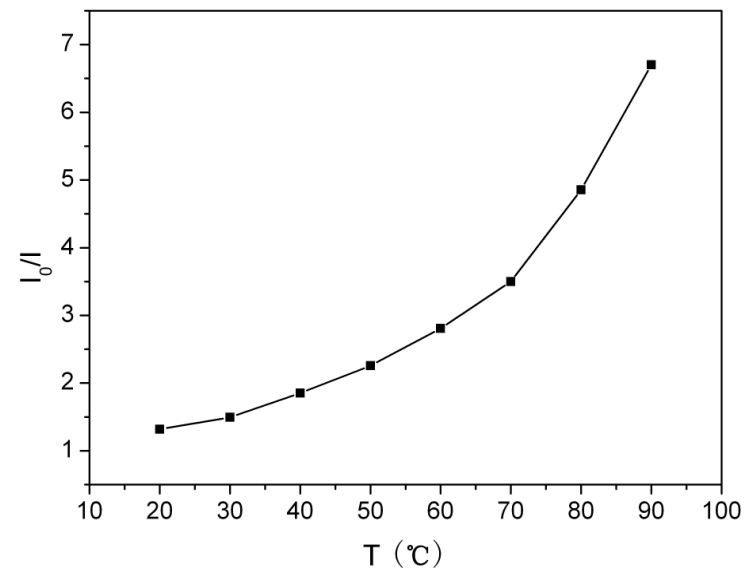

Figure 3. Effect of temperature on the fluorescence intensity of the sensor.

The sensor responses toward $\mathrm{Fe}^{3+}$

Red fluorescence emission can be observed with naked eyes when the grape skin is illuminated by a UV lamp. Anthocyanin is the well known fluorophore which can recognize and bind $\mathrm{Fe}^{3+}$ because of its special structure. It was thought to be that the fluorescent quenching occurred in a given concentration range of $\mathrm{Fe}^{3+}$ as $\mathrm{Fe}^{3+}$-anthocyanin complex was formed. The fluorescence emission spectra of the grape skin pigments and the sensor based on grape skin in the presence of different concentrations of $\mathrm{Fe}^{3+}$ were shown in Figure 4. It could be seen that the maximum emission wavelength of the grape skin pigments was at $680 \mathrm{~nm}$. When $1.0 \times 10^{-3} \mathrm{M} \mathrm{Fe}^{3+}$ was present, the fluorescence of grape skin pigments was completely quenched (see the insert of Figure 4). The emission wavelength of the grape skin also occurred at $680 \mathrm{~nm}$ and the fluorescence emission intensities of grape skin decreased considerably with the increase in the concentration of $\mathrm{Fe}^{3+}$, and no measurable spectral position shift is observed.

\section{Calibration curve}

The calibration curve can be established based on the linear relationship between fluorescence quenching $(I o / I)$ of the sensor and the logarithm of $\mathrm{Fe}^{3+}$ concentration in water, and the results are shown in Figure 5. The fluorescence intensity of the grape skin-based sensor increased linearly with increase of the $\mathrm{Fe}^{3+}$ concentration in the ranges of $1.0 \times 10^{-8}-1.0 \times 10^{-5} \mathrm{M}$ and 3.2 $\times 10^{-5}-3.2 \times 10^{-4} \mathrm{M}$, respectively. The corresponding linear equation can be expressed as $\mathrm{I}_{0} / \mathrm{I}=$ $1.79+0.0954 \log C(M)\left(r^{2}=0.9888\right)$ and $I_{0} / I=5.97+0.9917 \log C(M)\left(r^{2}=0.9856\right)$, and the 
detection limit (LOD) for $\mathrm{Fe}^{3+}$ was found to be $5.3 \times 10^{-9} \mathrm{M}$. A more obvious change in fluorescence intensity was observed when the concentration of $\mathrm{Fe}^{3+}$ solution was higher than 1.0 $\times 10^{-5} \mathrm{M}$. This might be caused by the change of $\mathrm{Fe}^{3+}$ ligands number [Scheme 1]. At the beginning of the interaction between $\mathrm{Fe}^{3+}$ and the grape skin pigments, the complex might be expressed as $\mathrm{Fe}$ (anthocyanin $)_{3}$ because the number of ligands was much more than that of $\mathrm{Fe}^{3+}$. However, with the increase of the concentration of $\mathrm{Fe}^{3+}$, the number of ligands was less than that of $\mathrm{Fe}^{3+}$, the molecular formula of complex was then changed to be $\mathrm{Fe}(\text { anthocyanin) })_{2} \cdot 1 / 2 \mathrm{SO}_{4}$ $[12,13]$.

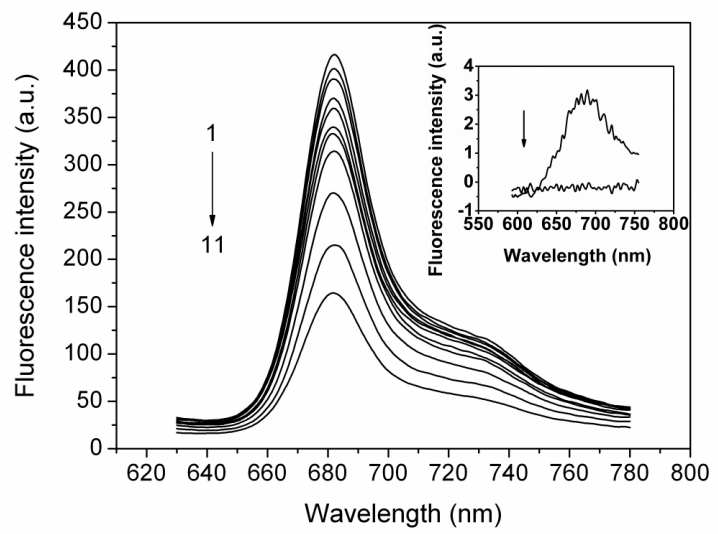

Figure 4. Fluorescence emission spectra of the grape skin-based sensor in the presence of different concentrations of $\mathrm{Fe}^{3+}$, and the $\mathrm{Fe}^{3+}$ concentration of curves 1 - 11: (1) blank solution; (2) $1.0 \times 10^{-8} \mathrm{M}$; (3) $3.2 \times 10^{-8} \mathrm{M}$; (4) $1.0 \times 10^{-7} \mathrm{M}$; (5) $3.2 \times 10^{-7} \mathrm{M}$; (6) 1.0 $\times 10^{-6} \mathrm{M}$; (7) $3.2 \times 10^{-6} \mathrm{M}$; (8) $1.0 \times 10^{-5} \mathrm{M}$; (9) $3.2 \times 10^{-5} \mathrm{M}$; (10) $1.0 \times 10^{-4} \mathrm{M}$; (11) $3.2 \times 10^{-4} \mathrm{M}$. The temperature was $60{ }^{\circ} \mathrm{C}$. Insert: fluorescence spectra of the grape skin pigments upon addition of $\mathrm{Fe}^{3+}\left(0\right.$ and $\left.1.0 \times 10^{-3} \mathrm{M}\right)$.

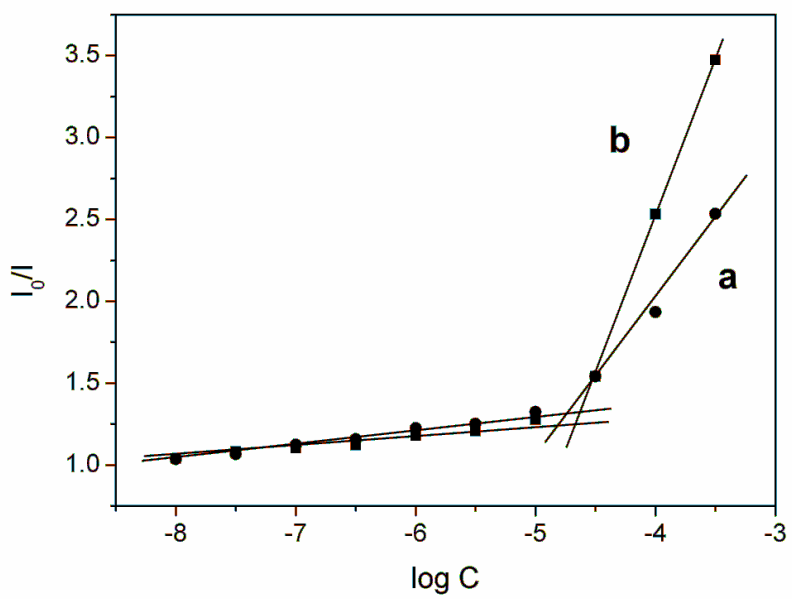

Figure 5. The calibration curve for $\mathrm{Fe}^{3+}$ determination (a) the sensor used in this experiment and (b) the sensor fabricated by another grape skin. 

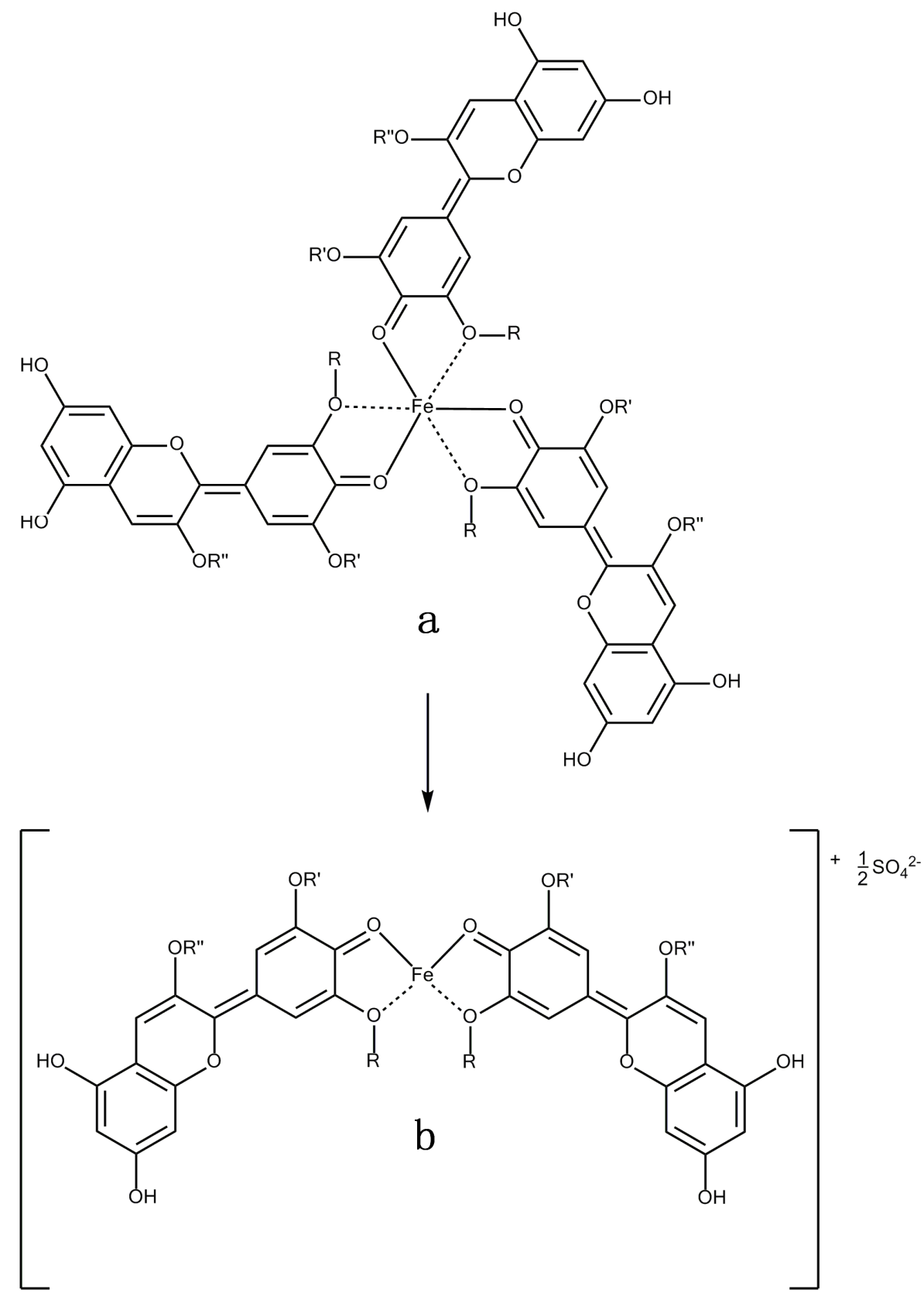

Scheme 1. The interaction between anthocyanin and $\mathrm{Fe}^{3+}$ when the concentration of $\mathrm{Fe}^{3+}$ was (a) below $1.0 \times 10^{-5} \mathrm{M}$ and (b) above $1.0 \times 10^{-5} \mathrm{M}$. 
In addition, it is worth mentioning that the working curve must be re-established if a new grape skin is used. The sensor is irreversible in this experiment. Fortunately, the fluorescence quenching behavior under the optimal conditions is the same (Figure 5).

\section{Interferences studies}

For the complexing capacity of the anthocyanin, the common cations and anions were chosen to determine their effect on the determination of iron(III). The tolerance limit was taken as the maximum concentration of foreign ions that caused a $5 \%$ deviation in the fluorescence intensity of the sensor when $\mathrm{Fe}^{3+}$ was present and its concentration was fixed at $1.0 \times 10^{-5} \mathrm{M}^{2} \mathrm{Cd}^{2+}, \mathrm{Sr}^{2+}$, $\mathrm{Mn}^{2+}, \mathrm{Ni}^{2+}, \mathrm{Mg}^{2+}, \mathrm{Ca}^{2+}, \mathrm{Na}^{+}, \mathrm{K}^{+}, \mathrm{Ba}^{2+}, \mathrm{Al}^{3+}, \mathrm{Cl}^{-}, \mathrm{NO}_{3}{ }^{-}, \mathrm{SO}_{4}{ }^{2-}, \mathrm{CO}_{3}{ }^{2-}, \mathrm{H}_{2} \mathrm{O}_{2}$, citrate at 200-fold concentration and $\mathrm{Cr}^{3+}, \mathrm{Pb}^{2+}, \mathrm{Hg}^{2+}, \mathrm{Co}^{2+}, \mathrm{NH}_{4}^{+}$at 50 -fold concentration of $\mathrm{Fe}^{3+}$ ions did not interfere.

\section{CONCLUSIONS}

The proposed method, based on the grape skin, is found to be useful for the determination of

$\mathrm{Fe}^{3+}$ with high sensitivity and selectivity, and it does not require complex pre-treatment or rigorous conditions. Therefore, the grape skin-based sensor has a great potential for the practical application.

\section{AKNOWLEDGEMENTS}

This work was supported by the National Natural Science Foundation of China (Grant No.20770505).

\section{REFERENCES}

1. Fan, L.J.; Jones, W.E. J. Am. Chem. Soc. 2006, 128, 6784.

2. Cha, K.W.; Park, K.W. Talanta 1998, 46, 1567.

3. Feng, L.H.; Chen, Z.B.; Wang, D.S. Spectrochim. Acta A 2007, 66, 599.

4. Askeland, R.A.; Skogerboe, R.K. Anal. Chim. Acta 1987, 192, 133.

5. Lafka, T.I.; Sinanoglou, V.; Lazos, E.S. Food Chem. 2007, 104, 1206.

6. Monagas, M.; Garrido, I.; Bartolomé, B.B.; Gómez-Cordovés, C. Anal. Chim. Acta 2006, $563,401$.

7. Revilla, I.; Pérez-Magariño, S.; González-SanJosé, M.L.; Beltrán, S. J. Chromatogr. A 1999, $847,83$.

8. McCallum, J.L.; Yang, R.; Young, C.; Strommer, J.N.; Tsao, R. J. Chromatogr. A 2007, $1148,38$.

9. Corrales, M.; García, A.F.; Butz, P.; Tauscher, B. J. Food. Eng. 2009, 90, 415.

10. Esparza, I.; Salinas, I.; Caballero, I.; Santamaría, C.; Calvo, I.; García-Mina, J.M.; Fernández, J.M. Anal. Chim. Acta 2004, 524, 215.

11. Castañeda-Ovando, A.; Pacheco-Hernández, M.L.; Páez-Hernández, M.E. Food Chem. 2009, 113, 859.

12. Hajji, H.E.; Nkhili, E.; Tomao, V.; Dangles, O. Free Radical Res. 2006, 40, 303.

13. Smyk, B.; Pliszka, B.; Drabent, R. Food Chem. 2008, 107, 1616. 